\title{
Evaluating spatially-explicit burn probabilities for strategic fire management planning
}

\author{
C. Miller ${ }^{1}$, M.-A. Parisien ${ }^{2.3}$, A. A. Ager ${ }^{4}$ \& M. A. Finney ${ }^{5}$ \\ ${ }^{1}$ USDA Forest Service, Rocky Mountain Research Station, \\ Aldo Leopold Wilderness Research Institute, USA \\ ${ }^{2}$ Natural Resources Canada, Canadian Forest Service, Canada \\ ${ }^{3}$ University of California, Berkeley, \\ Department of Environmental Science, Policy and Management, USA \\ ${ }^{4}$ USDA Forest Service, Pacific Northwest Research Station, \\ Western Wildland Environmental Threat Assessment Center, USA \\ ${ }^{5}$ USDA Forest Service, Rocky Mountain Research Station, \\ Missoula Fire Sciences Laboratory, USA
}

\begin{abstract}
Spatially explicit information on the probability of burning is necessary for virtually all strategic fire and fuels management planning activities, including conducting wildland fire risk assessments, optimizing fuel treatments, and prevention planning. Predictive models providing a reliable estimate of the annual likelihood of fire at each point on the landscape have enormous potential to support strategic fire and fuels management planning decisions, especially when combined with information on the values at risk and the expected fire impacts. To this end, a spatially-explicit modelling technique, termed 'burn probability' (BP) modelling, has been developed to simulate fires as a function of the physical factors that drive their spread - fuels, weather, and topography using the most sophisticated landscape-scale fire spread algorithms available. Despite several applications of the BP technique, much remains to be learned about their predictive ability. To achieve this goal, we are conducting experiments to not only unearth new discoveries about the complexities of fireenvironment relationships, but also to test and compare the relevance and accuracy of modelling approaches.
\end{abstract}

Keywords: burn probability, simulation modelling, strategic planning, wildland fire risk, fuel treatments. 


\section{Introduction}

Despite intensive fire suppression efforts, many parts of the world still experience large unplanned wildfires often deemed catastrophic. As long as humans live and work in fire-prone areas, wildfires will be perceived as a disruption. It is now common knowledge that even if we increase fire suppression expenditures substantially, it will not be possible - or ecologically desirable - to eradicate wildfires in fire-prone natural systems [1]. Therefore, successful co-existence with fire entails more effective risk management [2].

Better long-term planning requires a better understanding of where and when wildfires may occur. These are difficult questions to answer, as wildfire is a highly variable process for which different environmental controls play out at different spatial scales, from microsites to continents [3]. At the scale of a burning flame, fire is a physical process that is well understood. Likewise, the general understanding of fire behavior within vegetation stands or parcels can be fairly well predicted under known weather conditions. In contrast, we are only beginning to understand wildfire-environment relationships at the landscape scale $\left(10^{4}-10^{6} \mathrm{ha}\right)$, and reliable prediction of wildfire occurrence remains largely unachieved.

Spatially explicit information on the probability of burning is necessary for virtually all strategic fire and fuels management planning activities, including conducting wildland fire risk assessments, optimizing fuel treatments, and prevention planning. To meet this need, at least three models were independently developed and used to estimate probabilities of wildfire at the landscape scale [4-6]. These burn probability (BP) models represent a novel approach that integrates both stochastic and deterministic components of the fire regime. Here, we describe the general design of the BP technique and discuss its prior and potential applications for strategic (i.e., long-term) fire management planning.

\section{Model design}

All BP modeling techniques essentially simulate the effects of the ignition and spread of a very large number of fires on a raster landscape to calculate spatiallyexplicit landscape-level BP (Fig. 1). BP models represent a hybrid approach that simulate fire growth based on the physical factors that control fire spread (e.g., Farsite) with the larger-scale probabilistic components of fire regimes (e.g., spatial ignitions and fire weather conditions) on a landscape of known fuels and topography. The stochastic components are carefully modeled according to known temporal and spatial variability, as any departure from these trends can significantly affect resulting simulated fire patterns [7]. As in any simulation model, lack of data may be prohibitive in the BP approach.

Although each of the BP models generates fire probability maps as output, the manner in which inputs are treated may differ significantly among models. One model uses a least cost-distance algorithm to approximate the propensity for fire to spread across the landscape. In this model, BP is calculated by comparing the accumulated cost-distance of each cell according to the time available in the fire 
season and a pre-specified number and pattern of ignitions [4]. BP maps are generated from cost-distance surfaces developed for different weather conditions. The final BP map is an average of the BP maps, weighted according to the frequency of occurrence of weather conditions. The other two models explicitly simulate fire ignition and spread to compute BP (Fig. 1). First, the ignition locations and frequency are determined through an analysis of spatial fire patterns by cause and season. The fire weather conditions that drive fire spread as well as the length of the burning period are modeled stochastically from user-supplied distributions. This information is then relayed to the fire spread module. Fire spread is computed deterministically using a fire growth model or optimal spread algorithm to calculate fire spread through complex terrain and fuels.

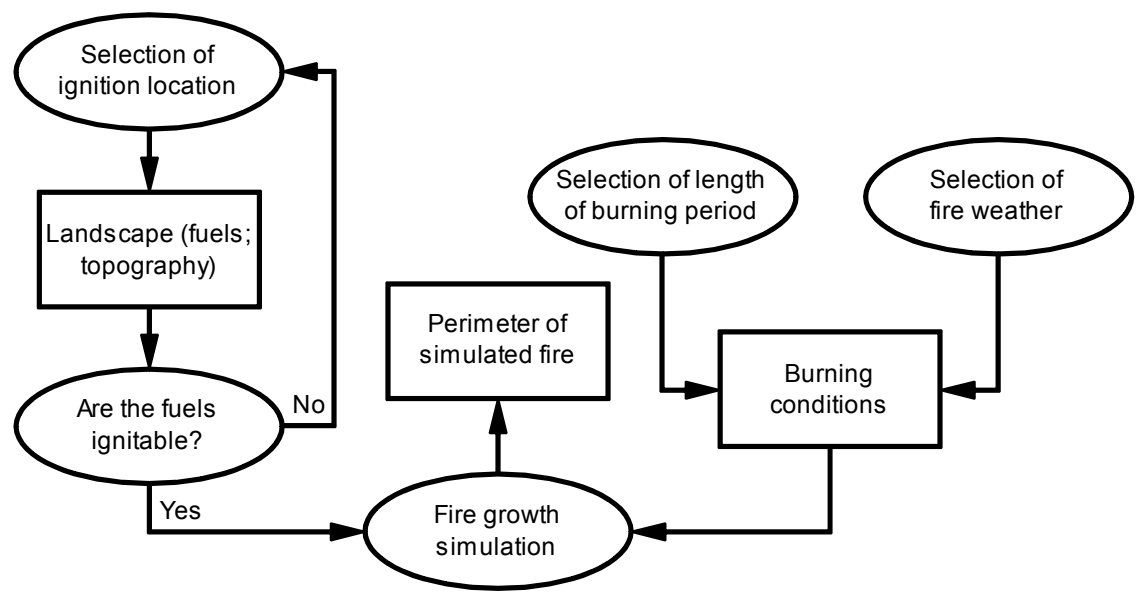

Figure 1: The simulation of individual fires in some burn probability models. Rectangular boxes represent model inputs/outputs and the elliptical boxes represent model processes. This process is repeated until the specified number of simulations is achieved. The number of ignitions per simulation is user-supplied.

The area that burns is recorded for each fire and ultimately compiled in a cumulative grid of area burned. The final product is a BP map where the BP of each cell $i$ is calculated as follows:

$$
B P_{i}=\frac{b_{i}}{N} \times 100
$$

where $b_{i}$ is the number of times cell $i$ burned and $N$ is the total number of simulations (typically $\geq 1000$ ). $B P_{i}$ represents the percent annual likelihood of cell $i$ being burned.

The BP technique was designed to capture the complexity of fire ignition and fire spread for a snapshot in time, as opposed to models that account for vegetation succession. The strength of these BP techniques is that they are rooted 
in accurate models of fire spread, allowing them to respond to fine-scale landscape patterns. By virtue of this characteristic, BP models not only account for the spatial and temporal distributions of ignitions, but also for the spatial context that affects wildland fire spread. The spatial topology of fire spread is particularly important in mapping fire risk, because changes in BP may occur well beyond a landscape feature that promotes or interrupts incoming fires [8].

\section{Applications to strategic fire management planning}

With a fairly reliable estimate of $\mathrm{BP}$, it is possible to evaluate the costs associated with wildland fire risk in a quantitative manner using the wellestablished probabilistic methods from the actuarial sciences [8]. For example, estimates of BP could be coupled with resource or financial values to estimate the expected losses or benefits from wildland fire and how the expected loss or benefit might be altered by proposed fuels treatments and/or fire management strategies. Without a quantitative measure of $\mathrm{BP}$, it is not possible to estimate the cost-effectiveness of management activities that may be proposed for mitigating or enhancing potential fire impacts [8]. The strength of using BP modeling for risk analysis is that it allows us to directly measure the change in expected losses or gains that result from landscape modifications, such as fuel treatment,
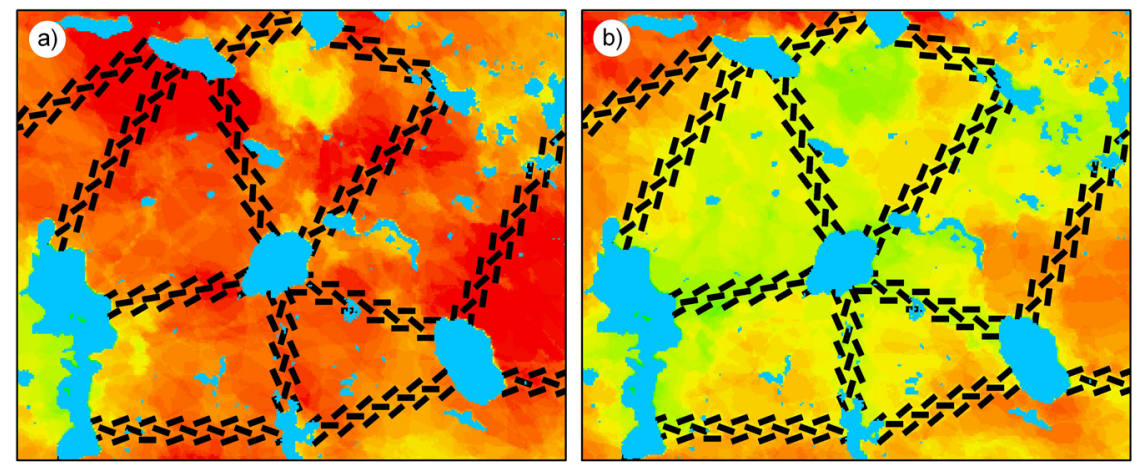

Burn probability $(\%)$
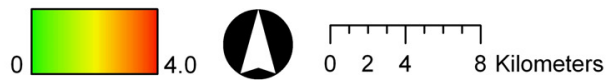

Figure 2: The annual burn probability of an untreated landscape of the boreal mixedwood of western Canada (a) and the same landscape with fuel treatments composed of less flammable fuels (b). The overlaid fuel treatments are shown in black. The untreated landscape was used to determine where to position the fuel treatments according to a specific rule-set that prioritized areas of high BP, the linking of large lakes (in blue), and the orientation of the treatments according to dominant wind direction during fireconducive events (from Parisien et al. [9]). 
wildfires, and land-use change. That is, this technique can be used for 'what if' scenarios by estimating BP before and after the inclusion of treatments.

Despite its recent development, the BP approach is currently being incorporated into fire risk assessments [10] and has been applied to several fire science and land-management problems. Finney [11] showed the relative effect of randomly treating fuels using repeated fire simulations, whereas other studies explicitly used BP maps to find the best placement of fuel treatments and subsequently evaluated their effect on fire likelihood $[9,12,13]$. Parisien et al. [9] showed that large non-flammable landscape features (lakes) could be used to link landscape-level fuel treatments to maximize their effectiveness (Figures 2 and 3). This modeling approach has also been used to evaluate the degree to which suppression activities that occur outside a wilderness area can affect the BP inside its boundaries [14], assess the risk to critical wildlife habitat [15], and estimate potential loss of timber values [16].

\section{Future research and development}

The BP approach is highly promising, but we are only beginning to understand the role of environmental and anthropogenic factors on fire probabilities, as their estimates represent a composite of numerous variables, many of which interact in complex ways. Finney [11,17] explored some of the effects of fuel treatment size, shape, and spatial configuration on fire spread in artificially generated landscapes, but many more factors presumably influence fire spread, such as the location of ignitions, the spatial and temporal variability in weather conditions, and the distribution of fire sizes. The effects of systematically varying the factors that drive BP must be evaluated over a range of landscape complexities, from simplistic artificial landscapes to highly diverse "real" landscapes. This will allow us to tease out the relative contribution of the environmental factors and their interactions. These results may help to bridge the gap between our understanding of the spread of individual wildfires and the variability in wildfires exhibited in natural fire regimes.

There is also a need to understand the relative sensitivity of each model to the different inputs and the concomitant effect on the output estimates of BP. As there is no single best design for a BP model, it is important to clarify for users which modeling approaches are most appropriate and practical for different applications. For example, the model using the least cost-distance algorithm is much more sensitive to the pattern of ignitions than the other two models, and as a result generates slightly different BP patterns on simple landscapes. However, it takes a fraction of the time to run compared to the other two models, and so may be more practical for certain applications. A systematic comparison of the respective methodologies is therefore crucial to sort out which set of modeling components provides the most robust estimate of BP for a given fire regime and set of objectives. 


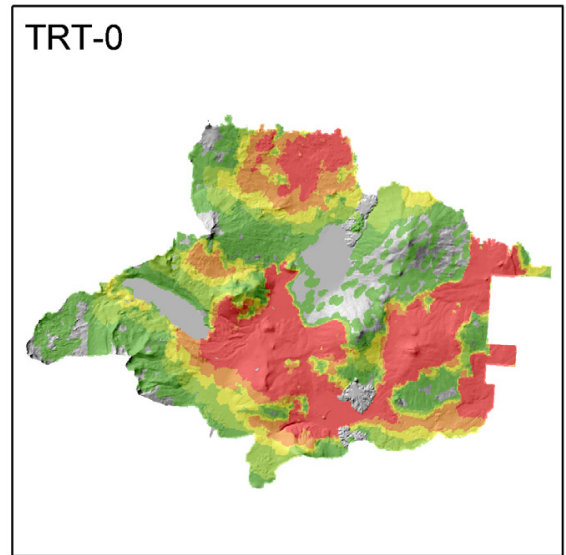

\section{TRT-10}

TRT-20

\section{TRT-50}
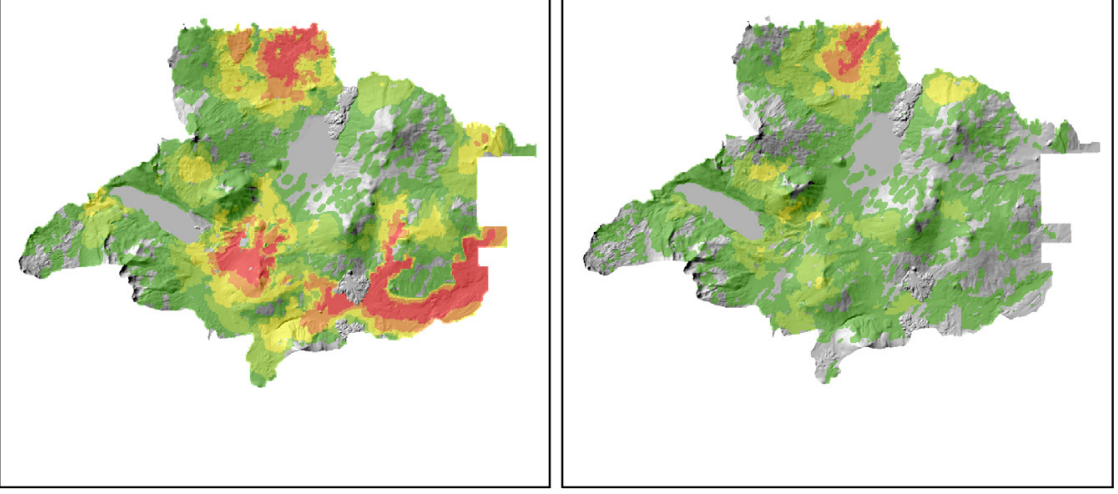

\section{Burn Probability

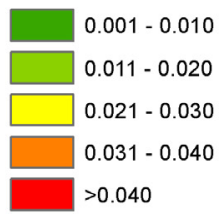

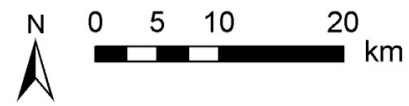

Figure 3: The effect of simulated fuel treatments on annual burn probability within the Five Buttes planning area in central Oregon, USA. Burn probabilities are shown for four management scenarios (TRT-0, TRT-10, TRT-20, and TRT-50) where fuel treatments were simulated on $0 \%, 10 \%, 20 \%$ and $50 \%$ of the study area, respectively. The wildfire simulation parameters, including wind direction, wind speed, fuel moisture, and temperature were chosen to replicate conditions during a recent severe fire within the planning area (from Ager et al. [15]). 


\section{References}

[1] McAlpine, R.S. \& Hirsch, K.G., An overview of LEOPARDS: The Level of Protection Analysis System. Forestry Chronicle, 75, pp. 615-621, 1999.

[2] Stephens, S.L. \& Ruth, L.W., Federal forest-fire policy in the United States. Ecological Applications, 15, pp. 532-542, 2005.

[3] Moritz, M.A., Morais, M.E., Summerell, L.A., Carlson, J.M. \& Doyle, J., Wildfires, complexity, and highly optimized tolerance. Proceedings of the National Academy of Sciences USA, 102, pp. 17912-17917, 2005.

[4] Miller, C., The spatial context of fire: a new approach for predicting fire occurrence. Proc. of the First National Congress on Fire Ecology, Prevention and Management. Eds. K.E.M. Galley, R.C. Klinger \& N.G. Sugihara, Tall Timbers Research Station: Tallahassee, FL, 2003.

[5] Finney, M.A., An Overview of FlamMap Fire Modeling Capabilities. Proc. of the First Fire and Fuels Conference: How to Measure Success. Department of Agriculture, Forest Service, Rocky Mountain Research Station: Fort Collins, CO, 2006.

[6] Parisien, M.-A., Kafka, V.G., Hirsch, K.G. Todd, J.B., Lavoie, S.G., \& Maczek, P.D., Mapping wildfire susceptibility with the BURN-P3 simulation model. Natural Resources Canada, Canadian Forest Service, Northern Forestry Centre, Edmonton AB, 2005.

[7] Lertzman, K., Fall, J. \& Dorner, B., Three kinds of heterogeneity in fire regimes: At the crossroads of fire history and landscape ecology. Northwest Science, 72, pp. 4-23, 1998.

[8] Finney, M.A., The challenge of quantitative risk analysis for wildland fire. Forest Ecology and Management, 211, pp. 97-108, 2005.

[9] Parisien, M.-A., Junor, D.R. \& Kafka, V.G., Comparing landscape-based decision rules for placement of fuel treatments in the boreal mixedwood of western Canada. International Journal of Wildland Fire, 16, pp. 664-672, 2007.

[10] Preisler, H.K., Brillinger, D.R., Burgan, R.E. \& Benoit, J.W., Probability based models for estimation of wildfire risk. International Journal of Wildland Fire, 13, pp. 133-142, 2004.

[11] Finney, M.A., Calculation of fire spread rates across random landscapes. International Journal of Wildland Fire, 12, pp. 167-174, 2003.

[12] Ager, A., Finney, M. \& McMahan, A., A wildfire risk modeling system for evaluating landscape fuel treatment strategies Proc. of the First Fire and Fuels Conference: How to Measure Success. Department of Agriculture, Forest Service, Rocky Mountain Research Station: Fort Collins, CO, 2006.

[13] Finney, M.A., A computational method for optimizing fuel treatment locations. International Journal of Wildland Fire, 16, pp. 702-711, 2007.

[14] Miller, C. \& Parsons, D., Can wildland fire use restore natural fire regimes in wilderness and other unroaded lands? Final report to the Joint Fire Science Program, project \#01-1-1-05, 2005, Online. http://leopold.wilderness.net/research/fprojects/pdfs/FinalReport_JFSP01_J an01_05.pdf 
[15] Ager, A.A., Finney, M.A., Kerns, B.K. \& Maffei, H., Modeling wildfire risk to northern spotted owl (Strix occidentalis caurina) habitat in Central Oregon, USA. Forest Ecology and Management, 246, pp. 45-56, 2007.

[16] Palma, C.D., Cui, W., Martell, D.L., Robak, D. \& Weintraub, A., Assessing the impact of stand-level harvests on the flammability of forest landscapes. International Journal of Wildland Fire, 16, pp. 584-592, 2007.

[17] Finney, M.A., Design of regular landscape fuel treatment patterns for modifying fire growth and behavior. Forest Science, 47, pp. 219-228, 2001. 